\section{Gold Catalysis: News from the}

\section{Homogeneous Wing}

\author{
A. Stephen K. Hashmi, Filiz Ata, Jan W. Bats, \\ M. Carmen Blanco, Wolfgang Frey, Melissa \\ Hamzic, Matthias Rudolph, Ralph Salathé, \\ Sascha Schäfer, Michael Wölfle \\ Institut für Organische Chemie, Universität Stuttgart, \\ Pfaffenwaldring 55, D-70569 Stuttgart, Germany \\ http://www.hashmi.de
}

\begin{abstract}
Phenol synthesis using a homogeneous gold catalyst serves as an example of the tremendous progress in homogeneous catalysis by gold which has been made in the past few years. Various aspects of this reaction, including catalyst selectivity and activity and the simple conditions used are described; and the mechanism is discussed in this context.
\end{abstract}

Since the previous COLD 2003 conference in Vancouver, interest in homogeneous catalysis with gold catalysts has increased significantly. More than 50 groups are now working in this field and the total number of publications has increased from less than 20 in the whole of 2004 to more than 40 during the first five months of 2006, while $95 \%$ of the current publications on gold catalysis describe reactions using heterogeneous catalysts. As far as innovation is concerned, the gap between homogeneous and heterogeneous catalysis is becoming smaller (1-7). Here we summarise results reported in the six posters we presented at GOLD 2006.

\section{Background}

One focus was the reaction of furans with terminal alkynyl groups in the side chain (8). This was chosen, as it is a beautiful case study for the achievements in recent years.

The reaction was discovered in 2000, and Figure 1 indicates an example of the early results for the reaction of the most typical test substrate $\mathbf{1}$ to produce the phenol $\mathbf{2}$.

This example demonstrates many of the features that are typical of homogeneous gold-catalysed reactions:

(1) While in heterogeneous catalysis very complex catalysts are used in most cases and the substrates are often quite simple small molecules (eg carbon monoxide), in homogeneous catalysis the catalyst can be relatively simple and the substrate tends to be complex.

(2) Often several bonds are broken (four bonds shown in red in 1) and several new bonds are formed (four bonds shown in green in 2). This direct conversion was previously not known in organic chemistry: only gold catalysis allows this direct transformation in an efficient manner.

(3) Typical catalyst loadings are somewhere between 1 and $5 \mathrm{~mol} \%$, which corresponds to 20-100 turnovers (turnover number TON). Reaction times are often in the range of hours, then the turnover frequencies (TOF) are significantly smaller than $100 \mathrm{~h}^{-1}$.

(4) There are numerous possible reaction pathways, but often the chemoselectivity is high and only one product is obtained.

(5) The reaction conditions are simple and robust, and neither absolute solvents nor the exclusion of air is needed.

What was the status of the $\mathrm{AuCl}_{3}$-catalysed conversion of 1 in 2000? One could summarize the initial features of the gold-catalysed phenol synthesis as follows:

+ Highly selective !

+ Simple conditions (no absolute solvents needed)

- Low catalyst activity (TON 48, TOF $\sim 10 \mathrm{~h}^{-1}$ )

- Mechanism unknown

- Functional group tolerance limited!

How did this initial picture change over the last few years?

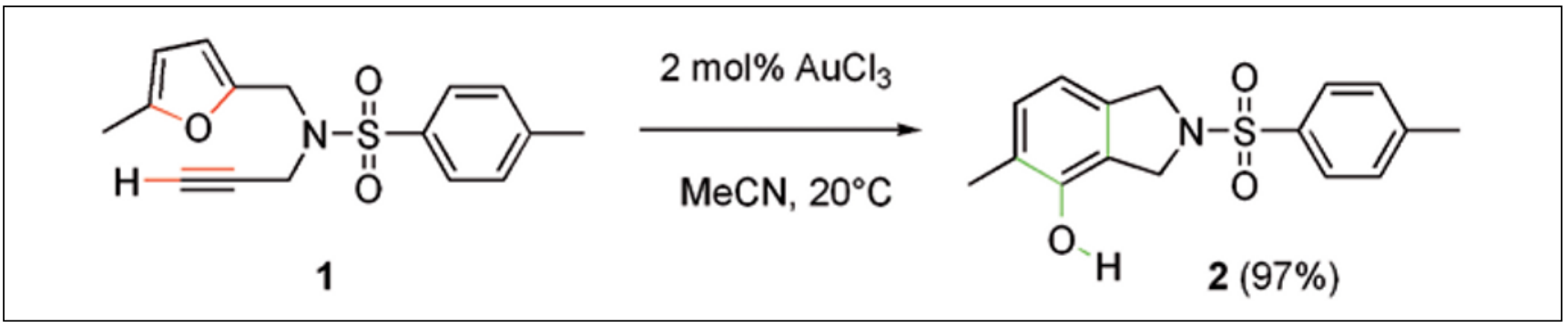

Figure 1

Gold-catalysed reaction of the test substrate 1 to produce the phenol 2. 


\section{Improving the Catalyst Activity}

First of all the catalyst activity urgently needed improvement. A variation of the metal was not successful (9): gold catalysts indeed are the best catalysts for this reaction. Instead of the simple $\mathrm{AuCl}_{3}$ (TON 48, TOF 10) a range of other gold complexes and other solvents was evaluated. This led to use of pyridine-type ligands, for example the anionic pyridine-2carboxylato ligands 3-6 shown in Figure 2 (10). With these ligands the catalyst loading could be reduced to as little as $0.07 \mathrm{~mol} \%$, the yield obtained then corresponded to a TON of 1200 .
We also tried to explore heterogeneous catalysts for these cycloisomerization reactions, but most of them completely failed. Among the unsuccessful "catalysts" were Au/C, Au/ $\mathrm{Fe}_{2} \mathrm{O}_{3}, \mathrm{Au} / \mathrm{SiO}_{2}, \mathrm{Au} / \mathrm{TiO}_{2}$ and Au-nanoparticles. Finally, Avelino Corma provided $\mathrm{Au}$ on nanocrystalline $\mathrm{CeO}_{2}$. With this heterogeneous catalyst a TON of 391 and a TOF of $16 \mathrm{~h}^{-1}$ was observed (11).<smiles></smiles>

3<smiles></smiles>

4<smiles></smiles>

7<smiles></smiles>

5<smiles></smiles>

6

Figure 2

With pyridine complexes 3-6 a much higher catalyst activity is obtained, catalyst $\mathbf{7}$ provides evidence for arene oxides as reaction intermediates.<smiles>C#CCCc1ccc(C)o1</smiles>

8

a 1,6-enyne

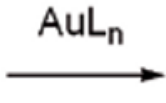

9

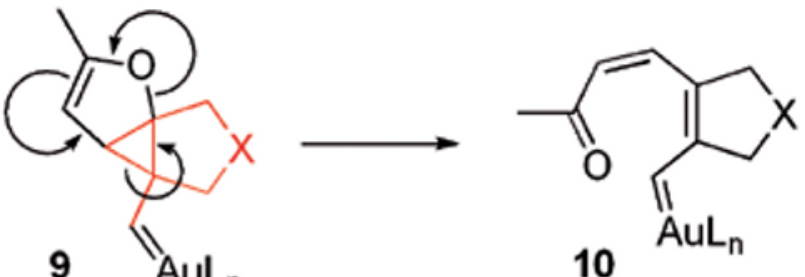

10<smiles>[X]C1CC2=CC=C(C#C)OC=C2C1</smiles><smiles>[X]CC1=C2C=CC(C)(CC)C2O1</smiles>
$11 \int$

\section{Figure 3}

Mechanism for the gold-catalysed phenol synthesis. 


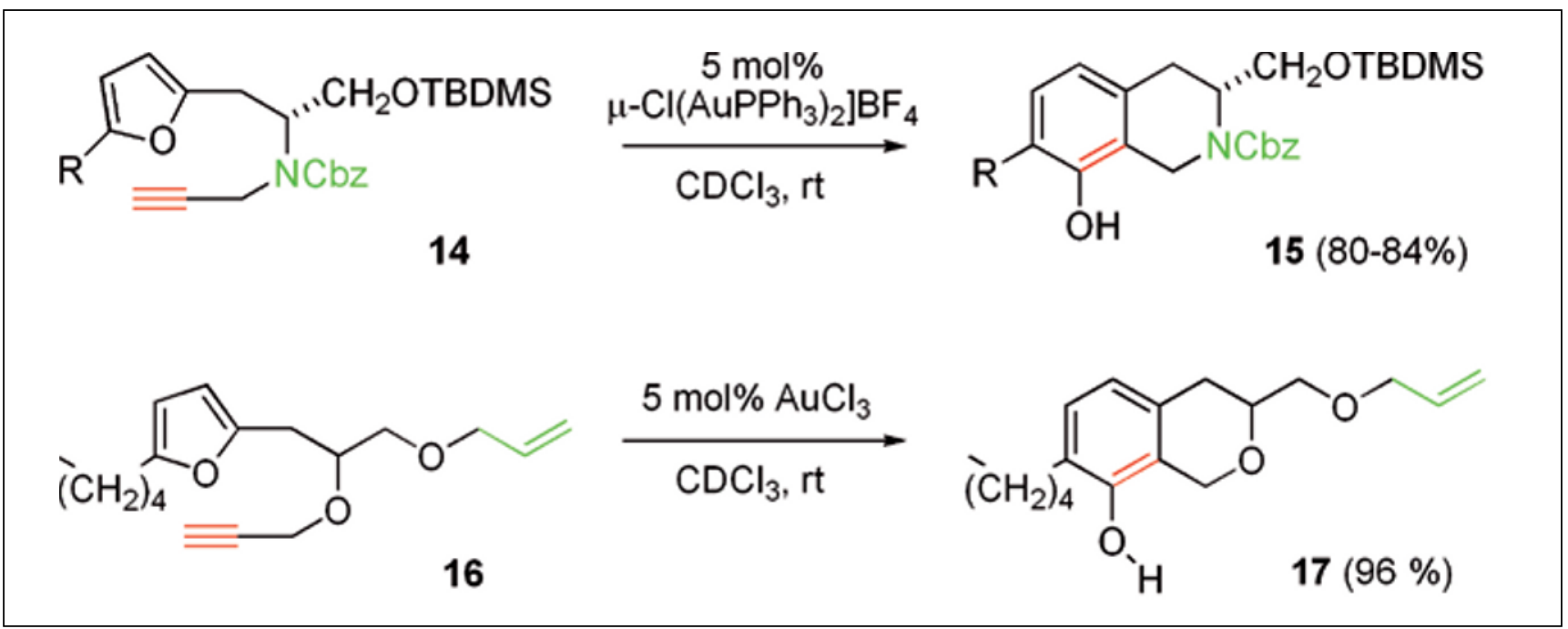

Figure 4

Different functional groups are tolerated.

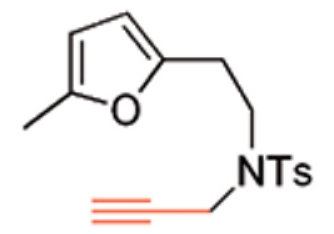

18

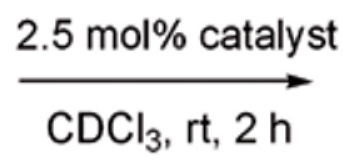

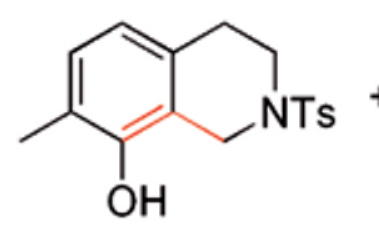

19<smiles>C=C1C[N+](C)(S)CCc2oc(C)cc21</smiles>

20

$$
\begin{array}{cr}
\text { catalyst } & \\
\left.\mu-\mathrm{Cl}[\mathrm{AuPPh}]_{3}\right]_{2} \mathrm{BF}_{4} & 59 \% \\
\left.\mu-\mathrm{Cl}[\mathrm{AuPMes}]_{3}\right]_{2} \mathrm{BF}_{4} & 72 \%
\end{array}
$$$$
15 \%
$$

Figure 5

Control of the chemoselectivity by the choice of a suitable ligand.

\section{Exploring the Mechanism}

Then the mechanism had to beaddressed. Early experiments indicated an intramolecular migration of the furan oxygen atom, which then becomes the phenolic oxygen atom (8). The breaking of four bonds and the forming of four new bonds is clearly not an elementary reaction with only one transition state. Initial efforts to detect an intermediate using in-situ nuclear magnetic resonance techniques at low temperature failed. Either only the starting material or, at temperatures above $0^{\circ} \mathrm{C}$, only the final product $\mathbf{2}$ was detectable when using the $\mathrm{AuCl}_{3}$ catalyst. This meant that the barrier of activation for the first step is the highest one, and once the molecules have passed through this, they convert to $\mathbf{2}$ in much faster subsequent steps. Then Echavarren, when using platinum catalysts, observed side-products which could be explained by platinum vinyl carbenoid intermediates analogous to 10 (12). Only recently have we been able to verify that similar sideproducts can come from gold catalysed reactions (13). Previously, with the gold catalysts, we had observed other side products deriving from later steps of the mechanism, and this only with bis(furyl)methanes (14). In 2004 we could prove that arene oxides $\mathbf{1 2}$ are intermediates in the reaction, based also on use of pyridine ligands in complexes of type 7 from Figure 2 (15). Thus today a relatively detailed mechanistic concept exists (Figure 3 ), the initial step of the reaction being similar to the wellknown enyne-cycloisomerization, with the further steps of the reaction mechanism making this a previously unknown mode of the enyne-cycloisomerization reaction - which again indicates the uniqueness of gold catalysts.

Regarding the organometallic and organic intermediates involved, this is a very innovative type of catalysis.

\section{Expanding the Functional Group Tolerance}

The last point to address was the functional group tolerance. Initially substrates such as $\mathbf{1}$ had a tosyl protecting group on nitrogen, which is difficult to remove. In the meantime the methodology had been applied to a total synthesis which uses no protecting group at all $(16,17)$, and also carbamate protected substrates had been used with success (Figure 4, 14) (18). Even 

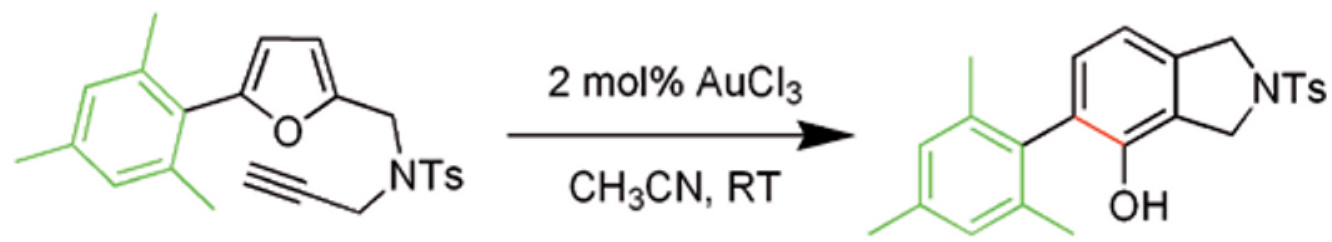

22

21 (79\%)

\section{Figure 6}

Steric hindrance does not prevent the gold-catalysed phenol synthesis.

with the simple $\mathrm{AuCl}_{3}$ catalyst (18) and in substrate 16 bearing both an alkynyl and an allyl group, the C-C triple bond reacts chemoselectively, and the C-C double bond is not touched under the reaction conditions shown in Figure $4(13,19)$.

The presence of a ligand on gold can, however, sometimes show a strong influence on the chemoselectivity of the process. For example, with the Uson-Laguna salt $\mu$ $\mathrm{Cl}\left[\mathrm{AuPPh}_{3}\right]_{2} \mathrm{BF}_{4}(20)$, a mixture of hydroarylation product $\mathbf{2 0}$ and phenol 19 was obtained from 18 (Figure 5). Switching to the Schmidbaur-Bayler salt $\mu$-Cl[AuPMes $\left.]_{2}\right]_{2} \mathrm{BF}_{4}(21)$ with the more bulky trismesitylphosphane ligand, high selectivity for the phenolic product 19 was re-established (22).

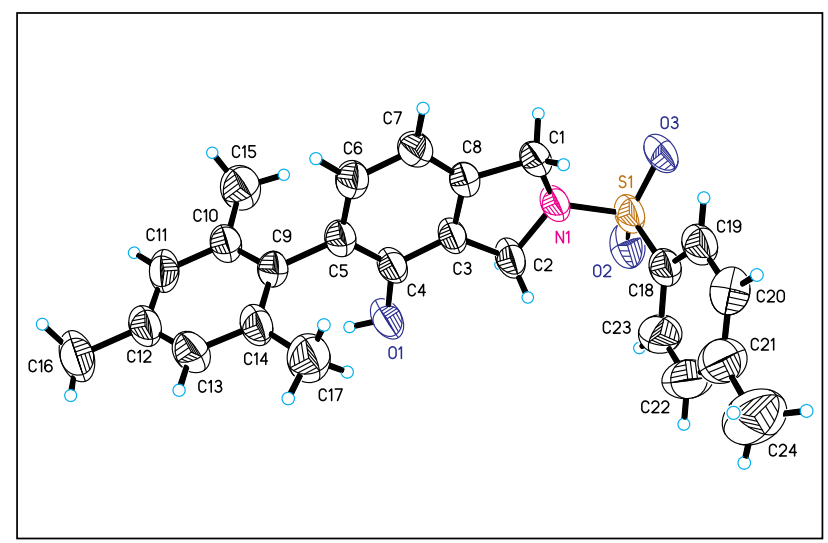

Figure 7

ORTEP plot of the solid state structure of $\mathbf{2 1 .}$

The reaction also tolerates significant steric hindrance, an adamantyl or even a mesityl substituent on the furan $\mathbf{2 2}$ (Figure 6, in green) is tolerated without any problem (23).

Here one new C-C bond (Figure 6, in red) to the mesityl carbon is formed, and this is usually a difficult task. As in many of the examples above, the structure of the products was unambiguously established by a single crystal structure analysis, which for $\mathbf{2 1}$ is shown in Figure 7. This nicely shows how the two ortho methyl groups shield the two carbon atoms of the biaryl junction.

\section{Conclusions}

The significant progress made in homogeneous catalysis by gold in the past few years is well illustrated by the example of the phenol synthesis described here: more active and more selective catalysts as well as a high functional group tolerance have been achieved, and quite a good insight into the mechanism obtained. The results also illustrate unique aspects of catalysis by gold.

\section{Acknowledgements}

We are very grateful to our sponsors DFG, Fonds der Chemischen Industrie, and Umicore AG \& Co KG (formerly OMG, dmc ${ }^{2}$, Degussa).

\section{About the Authors}

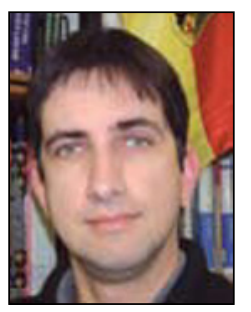

A. Stephen K. Hashmi is professor of organic chemistry at the Universität Stuttgart. He carried out his Diploma and $\mathrm{PhD}$ research with Professor G. Szeimies at the Ludwig-Maximilians-Universität München in the field of strained organic compounds such as allenes, bicyclobutanes and propellanes. His postdoctorate research with Professor B. M. Trost at Stanford University, California, covered transition metal catalysed reactions involving enyne metathesis. His Habilitation with Prof. J. Mulzer at the Freie Universität Berlin, the Johann Wolfgang GoetheUniversität Frankfurt and the Universität Wien, Austria, as well as visits at the University of Tasmania, Australia, and the Universität Marburg focused on both stoichiometric organometallic chemistry and transition metal catalysed organic reactions. Today, homogeneous gold-catalysed organic reactions are the major topic in the group at Universität Stuttgart.

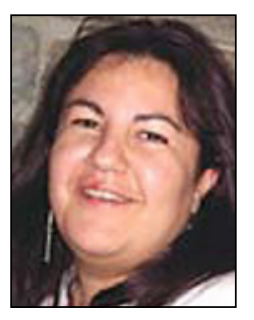

M. C. Blanco obtained her $\mathrm{PhD}$ in Logrono, Spain, and joined the group for two years as a postdoc in the AURICAT RTN of the European Union. She has now returned to Spain with a Juan de la Cierva fellowship, in Zaragoza she is still working on gold with Prof. A. Laguna. 


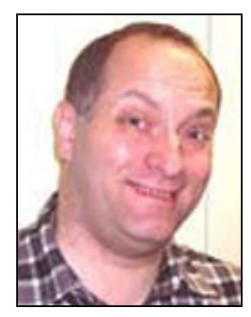

W. Frey is a specialist in X-ray crystallography at Stuttgart University.

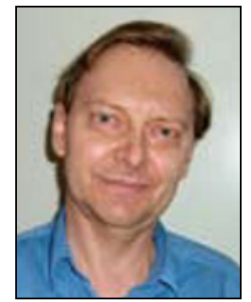

J. W. Bats holds a similar position at Frankfurt University, both have determined numerous structures for the group.
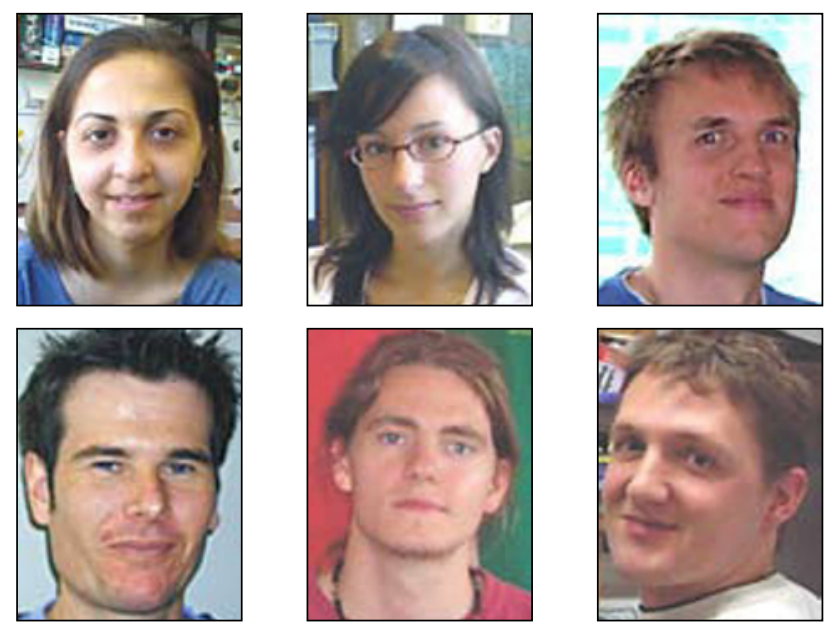

F. Ata, M. Hamzic, M. Rudolph, R. Salathé, S. Schäfer and $\mathbf{M}$. Wölfle are PhD students in the group who all studied in Stuttgart. S. Schäfer has spent six months at Zaragoza University as an Erasmus exchange student.

\section{References}

1 G. Dyker, Angew. Chem., 2000, 112, 4407; Angew Chem. Int. Ed., 2000, 39,4237

2 A.S.K. Hashmi, Gold Bull., 2003, 36, 3

3 A.S.K. Hashmi, Gold Bull., 2004, 37, 51

4 A. Arcadi and S. Di Giuseppe, Curr. Org. Chem., 2004, 8, 795

5 A. Hoffmann-Röder and N. Krause, Org. Biomol. Chem., 2005, 3, 387

6 A.S.K. Hashmi, Angew. Chem., 2005, 117, 7150; Angew. Chem. Int. Ed., 2005, 44, 6990

7 A.S.K. Hashmi and G.J. Hutchings, Angew. Chem., 2006, 118, 8064; Angew. Chem. Int. Ed., 2006, 45, 7896

8 A.S.K. Hashmi, T. M. Frost and J. W. Bats, J. Am. Chem. SoC., 2000, 122, 11553

9 A.S.K. Hashmi, T.M. Frost and J.W. Bats, Org. Lett., 2001, 3, 3769

10 A.S.K. Hashmi, J.P. Weyrauch, M. Rudolph and E. Kurpejovic, Angew. Chem., 2004, 116, 6707; Angew. Chem. Int. Ed., 2004, 43, 6545

11 S. Carrettin, M.C. Blanco, A. Corma and A.S.K. Hashmi, Adv. Synth. Catal., 2006, 348, 1283

12 B. Martín-Matute, D.J. Cardenas and A.M. Echavarren, Angew. Chem., 2001, 113, 4890; Angew. Chem. Int. Ed., 2001, 40, 4754

13 A.S.K. Hashmi, M. Wölfle, F. Ata, M. Hamzic, R. Sálate and W. Frey, Adv. Synth. Catal., 2006, 348, 2501

14 A.S.K. Hashmi, T.M. Frost and J.W. Bats, Catal. Today, 2002, 72, 19

15 A.S.K. Hashmi, M. Rudolph, J.P. Weyrauch, M. Wölfle, W. Frey, and J.W. Bats, Angew. Chem., 2005, 117, 2858; Angew. Chem. Int. Ed., 2005, 44, 2798

16 A.S.K. Hashmi, L. Ding, P. Fischer, J.W. Bats and W. Frey, Chem. Eur. J., $2003,9,4339$

17 A.S.K. Hashmi and L. Grundl, Tetrahedron, 2005, 61, 6231-6236

18 A.S.K. Hashmi, P. Haufe, C. Schmid, A. Rivas Nass and W. Frey, Chem. Eur. J., 2006, 12, 5376

19 A.S.K. Hashmi, J.P. Weyrauch, E. Kurpejovic, T.M. Frost, B. Miehlich, W. Frey and J.W. Bats, Chem. Eur. J., 2006, 12, 5806

20 R. Uson, A. Laguna and M.V. Castrillo, Synth. React. Inorg. Met.-Org. Chem., 1979, 9, 317

21 A. Bayler, A. Bauer and H. Schmidbaur, Chem. Ber./Recueil, 1997, 130, 115

22 A.S.K. Hashmi, M.C. Blanco, E. Kurpejovic, W. Frey and J.W. Bats, Adv. Synth. Catal., 2006, 348, 709

23 A.S.K. Hashmi, R. Salathé and W. Frey, Chem. Eur. J., 2006, 12, 6991 